\title{
Is Stent-Assisted Coil Embolization for the Treatment of Ruptured Blood Blister-Like Aneurysms of the Supraclinoid Internal Carotid Artery Effective? : An Analysis of Single Institutional Experience with Pooled Data
}

\author{
Haewon Roh, ${ }^{1}$ Junwon Kim, ${ }^{1}$ Sang-il Suh, ${ }^{2}$ Taek-Hyun Kwon, ${ }^{1}$ Wonki Yoon ${ }^{1}$ \\ Department of Neurosurgery, Guro Hospital, Korea University College of Medicine, Seoul, Korea \\ Department of Radiology, ${ }^{2}$ Guro Hospital, Korea University College of Medicine, Seoul, Korea
}

Objective : Given the high risk of rebleeding and recurrence of blood blister-like aneurysms (BBAs), we treated ruptured BBAs of the internal carotid artery (ICA) with stent-assisted coil embolization (SAC). This study aimed to evaluate the efficacy and safety of SACs.

Methods : We retrospectively reviewed clinical and radiological data from eight patients with ruptured BBAs of the supraclinoid ICA. The modified Rankin Scale (mRS) was used to assess clinical outcomes, while radiological outcomes were evaluated on angiographs. For a pooled analysis, data from literature reporting the outcomes of ruptured BBAs treated with SAC were collected and analyzed in conjunction with our data.

Results : In our cohort, the mean Raymond classification score was $1.57 \pm 0.53$ immediately after initial endovascular treatment. There were no perioperative complications or rebleeding events during the follow-up period. The mean $\mathrm{mRS}$ score at patient discharge was $1.00 \pm 0.81$ and improved to $0.28 \pm 0.48$ by the last follow-up day. The recurrence rate was $25 \%$ with an asymptomatic presentation and successful treatment with multiple stent insertion. Pooled analysis of 76 cases of SAC revealed a complete occlusion rate immediately after treatment of $54.8 \%$, rebleeding rate $7.94 \%$, and recurrence rate $24.2 \%$. Good clinical outcomes with $\mathrm{mRS}$ score $0-2$ were observed in $89.9 \%$ by the last clinical follow-up. Total mortality rate was $7.7 \%$.

Conclusion : This treatment appears to not only minimize the hemodynamic burden on the fragile dome specific to this type of aneurysm, but also provides an opportunity for safe and effective treatment in recurrent cases.

Key Words : Aneurysm, Blister-like · Embolization · Stent · Supraclinoid internal carotid artery.

\section{INTRODUCTION}

A blood blister-like aneurysm (BBA) of non-branching sites of the internal carotid artery (ICA) is a rare disease, accounting for approximately $0.3-1 \%$ of all intracranial aneurysms, and is

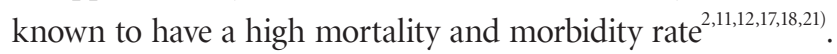
Diagnosis and treatment of BBAs are challenging due to their penchant for rapid morphological change and frequent rebleed-

- Received : June 18, 2020 •Revised : July 25, 2020 •Accepted : August 17, 2020

- Address for reprints : Wonki Yoon

Department of Neurosurgery, Guro Hospital, Korea University College of Medicine, 148 Gurodong-ro, Guro-ru, Seoul 08308, Korea

Tel : +82-2-2626-1178, Fax : +82-2-863-1684, E-mail : nvkumc@gmail.com, ORCID : https://orcid.org/0000-0003-3715-0718

This is an Open Access article distributed under the terms of the Creative Commons Attribution Non-Commercial License (http://creativecommons.org/licenses/by-nc/4.0) which permits unrestricted non-commercial use, distribution, and reproduction in any medium, provided the original work is properly cited. 
ing and recurrence ${ }^{12,17,20)}$. Numerous treatment methods have been suggested to treat BBAs, but a standard protocol has not yet been established ${ }^{2,911,13,21)}$.

Our institute has treated BBA patients with stent-assisted coil embolization (SAC), wherein a single or double-overlaying self-expandable laser-cut stent and loose coil packing is deployed into the aneurysm. This study aims to evaluate the efficacy and safety of this technique in patients with ruptured BBAs of the supraclinoid ICA. Due to the limitations of data collected from a single institution with a small sample size, we pooled and analyzed the data of other studies reporting the outcomes of SAC in patients with similar case presentations. To the best of our knowledge, this study is the first pooled analysis of SAC outcomes in treating ruptured supraclinoid ICA BBAs.

\section{MATERIALS AND METHODS}

Institutional Review Board acceptance was obtained and the need for informed consent was waived due to the retrospective nature of the study.

\section{Patient selection}

Between January 2008 and December 2017, 783 patients with ruptured intracranial aneurysms were admitted to Guro Hospital, Korea University. Of these patients, 171 had ruptured ICA aneurysms. Ruptured BBAs were identified in 11 of the 171 patients. The following angiographic criteria had to be met for the aneurysm to be classified as a BBA and for inclusion in this study : 1) the ruptured aneurysm must be located at a nonbranching site of the supraclinoid ICA. 2) The aneurysm must have a broad neck. And 3) rapid growth or morphological change of the aneurysm must be confirmed on serial angiographic studies.

Three patients were excluded because one died immediately after diagnosis of his ruptured BBA and two were treated by inserting the overlaying stents without any coil due to insufficient space for coil deployment. Thus, a total of eight patients were enrolled in this study.

\section{Outcome measurement}

We reviewed clinical, procedural, and radiological data. The clinical data included the Glasgow coma scale (GCS) at patient admission and discharge, the occurrence of rebleeding, and the modified Rankin Scale (mRS) at discharge, and the last follow-up. Procedural data included the stents and coils used and periprocedural complications, including thromboembolic or hemorrhagic complications and the grade of aneurysm occlusion as determined by the modified Raymond classification. Radiological data included geometrical measurements of the aneurysms and recurrence and Raymond classification scale per the last follow-up angiography. The endpoints of analysis included a good clinical outcome (mRS 0-2) after treatment. The secondary outcome was rebleeding, recurrence.

\section{Endovascular procedure and management proto- col}

All endovascular treatments were conducted under general anesthesia. A 6 or 7-Fr Shuttle guiding catheter was placed at the cervical ICA. The distal-access intermediate catheter was positioned in the horizontal segment of the petrous ICA. The Prowler select plus ${ }^{\mathrm{TM}}$ microcatheter (Codman, Raynham, MA, USA) was used for intracranial stent deployment. Available microcatheters were used for coil deployment.

In all cases, the jail technique was used. After confirmation of stable microselection of the ruptured aneurysm, the intracranial stent was deployed via a previously placed stent delivery catheter. In the initial treatment of all cases, low profile, self-expandable laser-cut stents were used (Enterprise ${ }^{\circledR}$ stent in seven cases; Codman, Miami Lakes, FL, USA and Neuroform EZ stent in one case; Stryker, Fremont, CA, USA). The deployment of the stents was followed by insertion of bare platinum coils placed loosely into the aneurysm, mainly near the neck and proximal body, to minimize the risk of re-rupture of the aneurysm. When the first coil was deployed, intravenous heparin was administered to achieve a target activated clotting time of 150-200 seconds, which is more generous than the target clotting time in SAC of unruptured saccular aneurysms, to minimize the risk of rebleeding. In all cases, an immediate post-operative computed tomography (CT) scan was performed to check for any hemorrhagic complications. A loading dose of $500 \mathrm{mg}$ of acetylsalicylic acid and $300 \mathrm{mg}$ of clopidogrel were administered immediately after the procedure. We performed each procedure without pre-medication with antiplatelet drugs due to the high risk of BBA re-rupture. 


\section{Pooled analysis}

Using PubMed, MEDLINE, and Google Scholar, we performed a literature search for all articles between the years of 2005 and 2018 that included the terms "blood-blister aneurysm" and/or "blister aneurysm" and described aneurysms of the ICA. Articles were limited to the English language with human subjects diagnosed with an ICA BBA and treated primarily with SAC. Articles that described enrolled patients treated with other endovascular treatments, such as sole-stenting or flow diverters, were excluded. Case reports, case series, and other retrospective studies were included, while editorials, commentaries, and reviews were excluded. This search was supplemented by manually searching reference lists within all relevant articles. These articles were further selected based on the inclusion of more than three cases and the presentation of individualized details for each endovascular treatment and outcomes after treatment. Studies lacking individualized details or that did not evaluate outcomes using mRS or Glasgow outcome scale were excluded. A total of 68 cases described in seven articles were selected. The information entered into this analysis included 1) the year of publication, 2) the number of patients treated by SAC, 3) the sex of the patients, 4) the preoperative neurological status (Hunt-Hess grade), 5) the number of stents used for stent-assisted coiling, 6) the immediate angi-

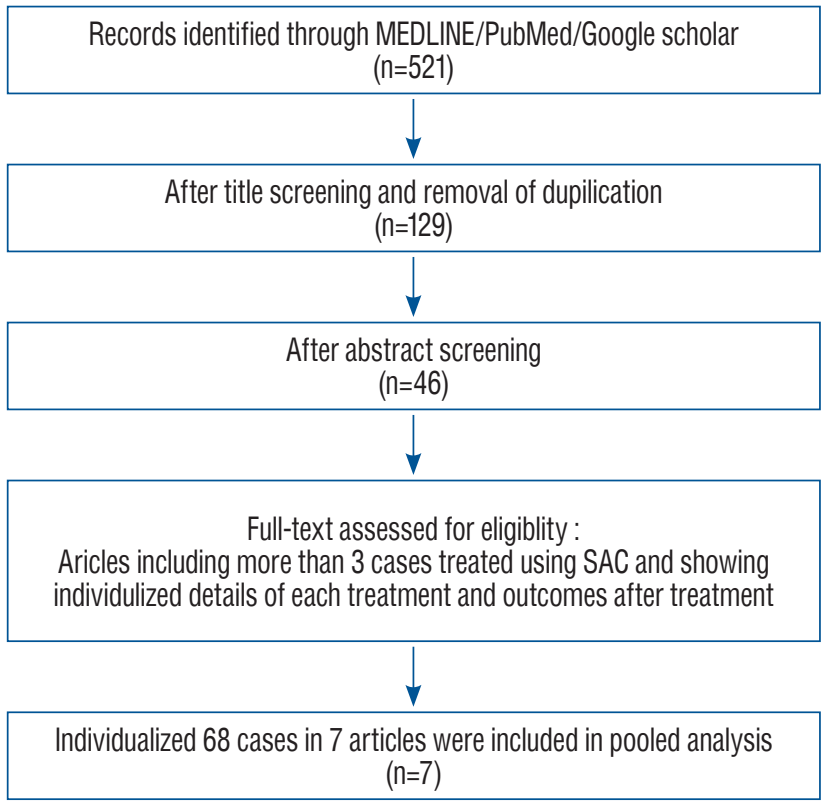

Fig. 1. The literature selection process for the pooled analysis of SAC in the treatment of ruptured blood blister-like aneurysms. SAC : stentassisted coil embolization.

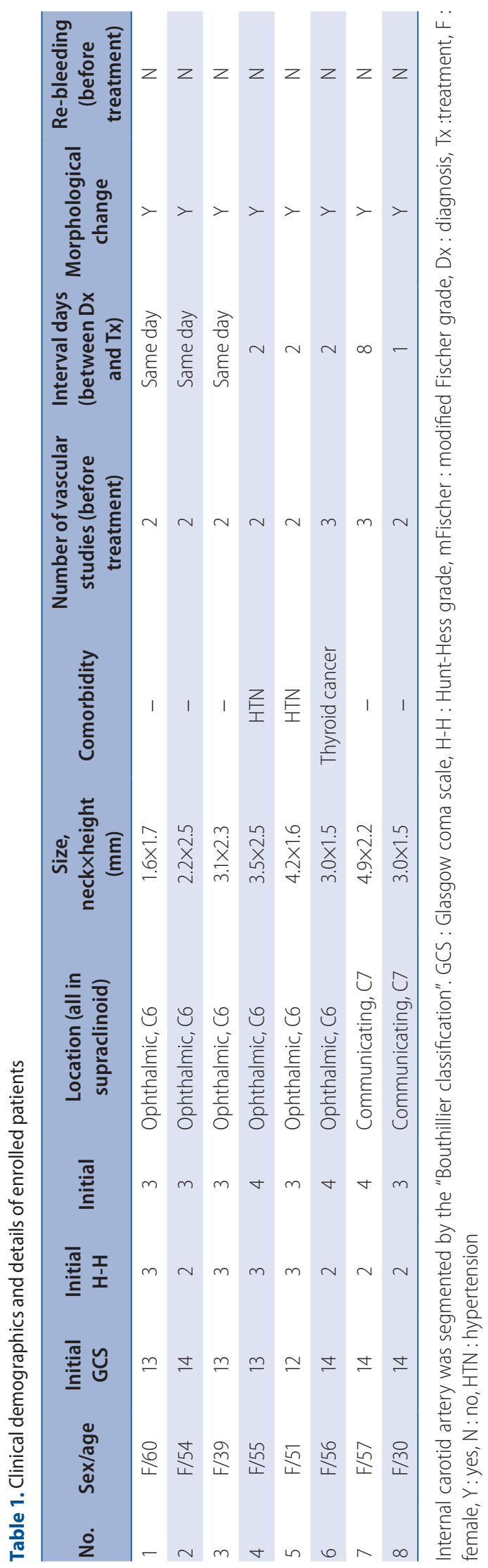


ographic result, 7) the occurrences of rebleeding after treatment, 8) the angiographic follow-up result, 9) the clinical outcome at the last follow-up, 10) mortality, and 11) the clinical and radiological outcomes of retreatment cases. The article selection process is shown in Fig. 1.

\section{Statistical analysis}

aStatistical analyses were performed using the SPSS version 23 software (IBM, Chicago, IL, USA). Continuous variables were expressed as a mean or median with a standard deviation. Categoric variables were expressed as frequencies with percentages.

\section{RESULTS}

\section{Our cohort}

The demographic and clinical data of our eight patients are summarized in Table 1 . The mean patient age was $50.25 \pm 10.33$ years (range, 30-60). The initial median GCS was $13.38 \pm 0.74$ (range, 12-14). The initial median Hunt-Hess grade score was $2.50 \pm 0.53$ (range, 2-3) and the initial median modified Fisher grade was $3.00 \pm 0.52$ (range, $3-4$ ). Six patients had right-sided BBAs, while the others had left-sided lesions.

All aneurysms were wide-necked with an average neck diameter of 3.18 $\pm 1.04 \mathrm{~mm}$ (range, 1.6-4.9) and height of 1.97 \pm $0.44 \mathrm{~mm}$ (range, 1.5-2.5). All BBAs showed morphological change or enlargement of the lesion in serial vascular studies before initial treatment. The mean interval between the diagnosis of subarachnoid hemorrhage (SAH) and initial endovascular treatment was $1.87 \pm 2.64$ days. There was no rebleeding before treatment.

Table 2 summarizes radiological, procedural, and clinical outcomes. Double stenting with coil embolization was performed on four patients, while the other four patients underwent single SAC; in all cases, we performed single SAC preferably in order to avoid a prolonged procedural time and minimize the use of heparin during endovascular procedure.

Table 2. Summary of the endovascular treatments with clinical and angiographic outcomes

\begin{tabular}{|c|c|c|c|c|c|c|c|c|c|}
\hline No. & $\begin{array}{l}\text { Stent (count) : } \\
\text { name, size }\end{array}$ & $\begin{array}{l}\text { Coil, count/ } \\
\text { total length } \\
(\mathrm{cm})\end{array}$ & $\begin{array}{l}\text { Initial } \\
\text { Raymond } \\
\text { scale }\end{array}$ & $\begin{array}{c}\text { mRS (at } \\
\text { discharge) }\end{array}$ & $\begin{array}{l}\text { Clinical f/u } \\
\text { period (days) }\end{array}$ & $\begin{array}{c}\text { mRS (at the } \\
\text { latest } f / u \text { ) }\end{array}$ & $\begin{array}{c}\text { Recurrence } \\
\text { (postoperative day) }\end{array}$ & $\begin{array}{c}\text { Vascular } \\
\text { study f/u } \\
\text { period (days) }\end{array}$ & $\begin{array}{c}\text { Angiographic } \\
\text { outcome } \\
\text { (at the latest) }\end{array}$ \\
\hline 1 & $\begin{array}{c}\text { Enterprise (2) : } \\
4.0 \times 16 \mathrm{~mm} \\
4.0 \times 23 \mathrm{~mm}\end{array}$ & $1 / 3$ & 2 & 0 & NA & NA & NA & F/U loss & NA \\
\hline 2 & $\begin{array}{c}\text { Enterprise (1) : } \\
4.0 \times 23 \mathrm{~mm}\end{array}$ & $3 / 10$ & 1 & 1 & 540 & 1 & N & 540 & $\begin{array}{l}\text { Complete } \\
\text { resolution }\end{array}$ \\
\hline 3 & $\begin{array}{c}\text { Enterprise (1) : } \\
4.0 \times 23 \mathrm{~mm}\end{array}$ & $3 / 9$ & 2 & 1 & 662 & 0 & $Y(180)$ & 662 & $\begin{array}{l}\text { Complete } \\
\text { resolution } \\
\text { Complete }\end{array}$ \\
\hline 4 & $\begin{array}{c}\text { Neuroform (2): } \\
4.5 \times 20 \mathrm{~mm} \\
4.5 \times 30 \mathrm{~mm}\end{array}$ & $5 / 7$ & 2 & 1 & 490 & 0 & NA & $N A^{*}$ & $N A^{*}$ \\
\hline 5 & $\begin{array}{c}\text { Enterprise (2) : } \\
4.5 \times 28 \mathrm{~mm} \\
4.5 \times 28 \mathrm{~mm}\end{array}$ & $4 / 9$ & 1 & 0 & 1310 & 0 & $\mathrm{~N}$ & 1064 & $\begin{array}{l}\text { Complete } \\
\text { resolution }\end{array}$ \\
\hline 6 & $\begin{array}{l}\text { Enterprise (1) : } \\
4.0 \times 3.0 \mathrm{~mm}\end{array}$ & $3 / 10$ & 1 & 2 & 1064 & 0 & $Y(150)$ & 501 & $\begin{array}{l}\text { Complete } \\
\text { resolution }\end{array}$ \\
\hline 7 & $\begin{array}{r}\text { Enterprise (2) : } \\
4.0 \times 23 \mathrm{~mm} \\
4.0 \times 3.0 \mathrm{~mm}\end{array}$ & $2 / 7$ & 2 & 2 & 505 & 1 & $\mathrm{~N}$ & 392 & $\begin{array}{l}\text { Complete } \\
\text { resolution }\end{array}$ \\
\hline 8 & $\begin{array}{c}\text { Enterprise (1): } \\
4.0 \times 23 \mathrm{~mm}\end{array}$ & $2 / 6$ & 2 & 1 & 408 & 0 & N & 393 & $\begin{array}{l}\text { Complete } \\
\text { resolution }\end{array}$ \\
\hline
\end{tabular}

*The case 4 patient refused a follow-up digital subtraction angiography for economic reasons. mRS : modified Rankin Scale, f/u : follow-up, NA : not available, $\mathrm{N}$ : no, $\mathrm{Y}$ : yes 
However, in the cases that showed significant aneurysmal filling after single stent assisted coiling, we performed an additional stent deployment to make more flow-diversion effect. We inserted an average of 1.5 stents for each treatment of ruptured BBA. In seven cases, Enterprise stents were used. In all cases, the packing of the coil into the aneurysm was loose to achieve bare isolation of the aneurysm. The average total length of deployed coils per treatment was $7.62 \pm 2.38 \mathrm{~cm}$ (range, $3-10)$. In case No. $4-8$ (5/8, 62.5\%), because only very tiny pouch that can barely indicate rupture point was observed at their initial diagnosis, immediate endovascular procedure could not be performed. However, after ruptured sac of BBAs changed their shape and size which could be enough to be packed with some of small coils during several days after diagnosis, they could be treated with SAC. The mean Raymond scale score immediately postoperatively was $1.62 \pm 0.51$ with five patients scoring two and three patients scoring one. The rate of incomplete coil embolization, represented by a grade other than one on the modified Raymond scale, was $62.5 \%$ (five out of eight). At discharge, all patients displayed good clinical outcomes - two patients had mRS of 0 , four had mRS of 1 , and two had mRS of 2 . The mean mRS at discharge was 1.000 .75 . By the last follow-up assessment, the mean mRS had improved to 0.250 .46 (mean clinical follow-up, 711.29土 341.11 days; range, 408.0-1310.0).

Follow-up digital subtraction angiography (DSA) was conducted in six cases. The angiographic follow-up took place at a mean of 592.00 \pm 252.30 days (range, 392.0-1064.0) after discharge. Two patients (cases 3 and 6), or 33.33\%, developed asymptomatic recurrence of treated BBA on the 180th and 150th days post-treatment, respectively. The recurrent cases were treated with two additional overlapping LVIS Blue ${ }^{\mathrm{TM}}$ stents (Microvention, Tustin, CA, USA) within the previously inserted stent. There were no cases of rebleeding or in-stent restenosis during the follow-up period. All six cases showed complete healing of the diseased segment at the last angiographic follow-up.
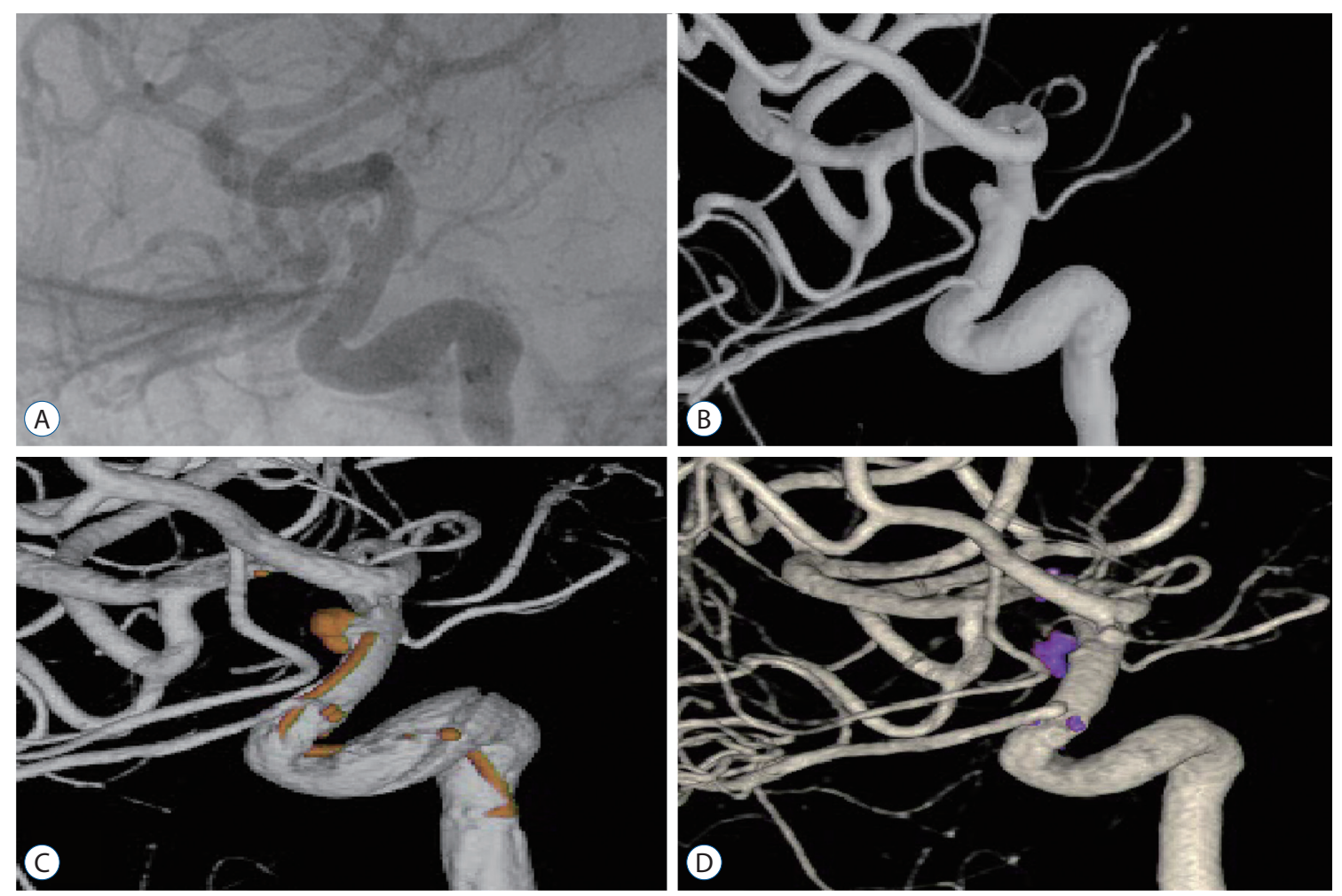

Fig. 2. Digital subtraction angiography (DSA) images of case 8. DSA revealed a ruptured aneurysm at the communicating segment of the right supraclinoid internal carotid artery (A and B). A Raymond classification score of 2 was achieved immediately after treatment (C). Follow-up angiography 1 year after initial treatment showed complete occlusion of the treated aneurysm (D). 


\section{Illustrative cases}

\section{Case No. 8}

A 30-year-old female arrived at the emergency room complaining of a severe headache. A CT scan showed diffuse SAH. The Hunt-Hess score was two and the modified Fisher grade score was three. DSA revealed a ruptured aneurysm at the communicating segment of the right supraclinoid ICA (Fig. $2 \mathrm{~A}$ and $\mathrm{B})$. Emergency endovascular treatment occurred using a single Enterprise ${ }^{\circledR}$ stent (Codman, Miami Lakes, FL, USA) with deployment of two detachable coils into the ruptured aneurysm. A Raymond classification scale of two was achieved immediately after treatment (Fig. 2C). There were no complications related to the procedure and no evidence of recurrence or rebleeding in the early stages of follow-up with serial vascular studies. The final follow-up angiography completed 1 year after initial treatment showed complete occlusion of the treated aneurysm (Fig. 2D).

\section{Case No. 3}

A 39-year-old female arrived at the emergency room complaining of drowsiness. CT angiography (CTA) revealed a tiny, ruptured BBA with a height of $1 \mathrm{~mm}$ in the ophthalmic segment of the right supraclinoid ICA. Two hours after CTA,

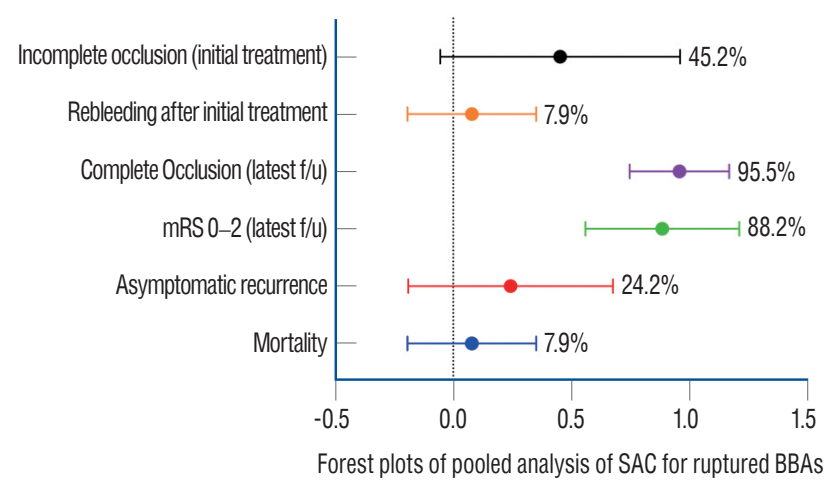

Fig. 4. Forest plot summarizing the pooled analysis of stent-assisted coil embolization for ruptured BBAs from the literature. $\mathrm{f} / \mathrm{u}$ : follow-up, $\mathrm{mRS}$ : modified Rankin Scale, SAC : stent-assisted coil embolization, BBAs : blood blister-like aneurysms.
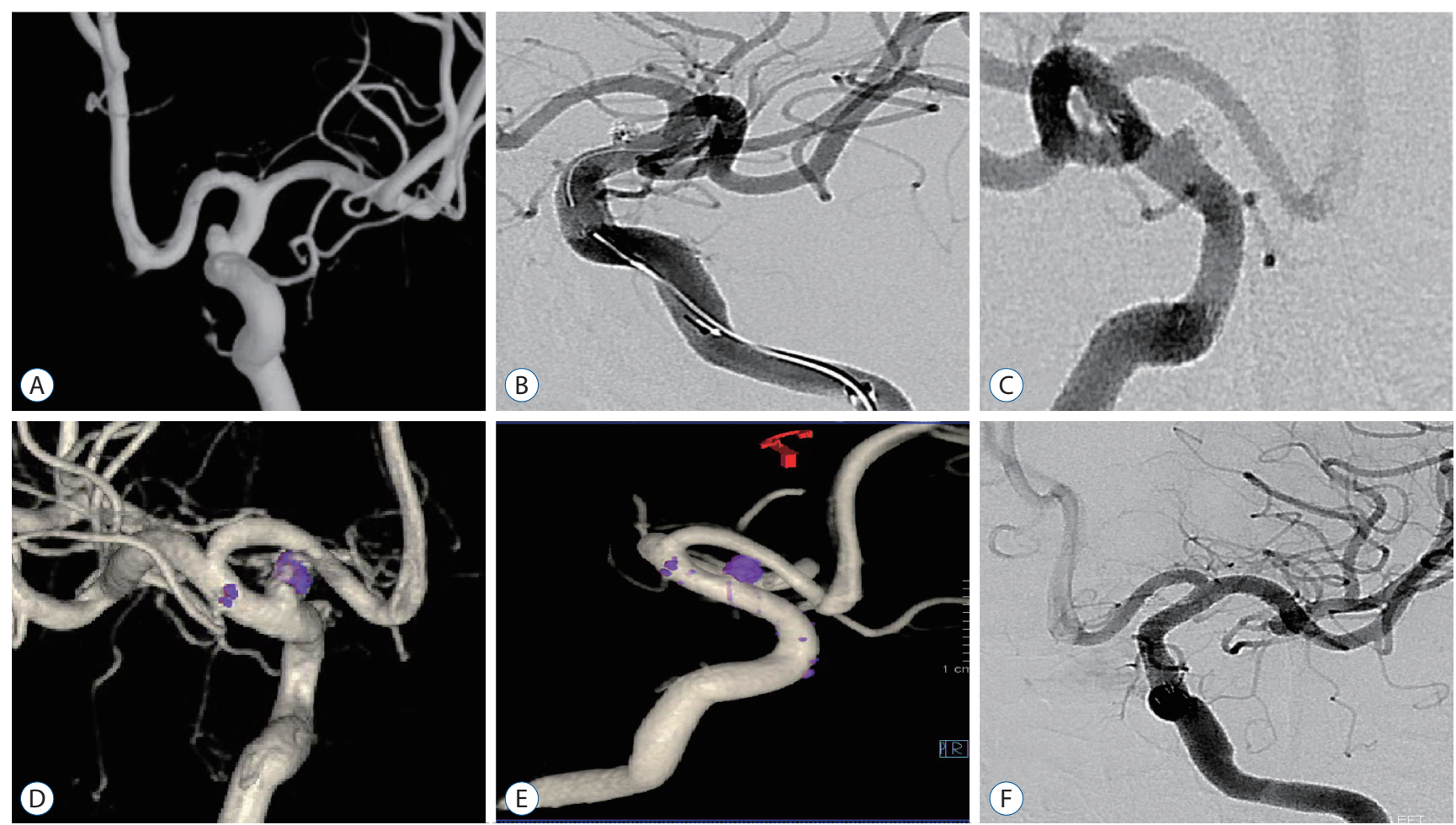

Fig. 3. Digital subtraction angiography images of case 3. DSA revealed a ruptured aneurysm with a relatively wide neck (3.1 mm) and short height (2.3 $\mathrm{mm}$ ) (A). A single Enterprise stent was inserted for neck remodeling and three coils were packed into the aneurysmal sac. A Raymond classification of 2 was achieved (B). Six months after the initial endovascular treatment, asymptomatic recurrence of the treated blood blister-like aneurysm was observed ( $C$ and D). After retreatment, gradual improvement and, eventually, complete angiographic cure of the recurred aneurysm was observed in the followup serial DSA studies (E and F). DSA : digital subtraction angiography. 


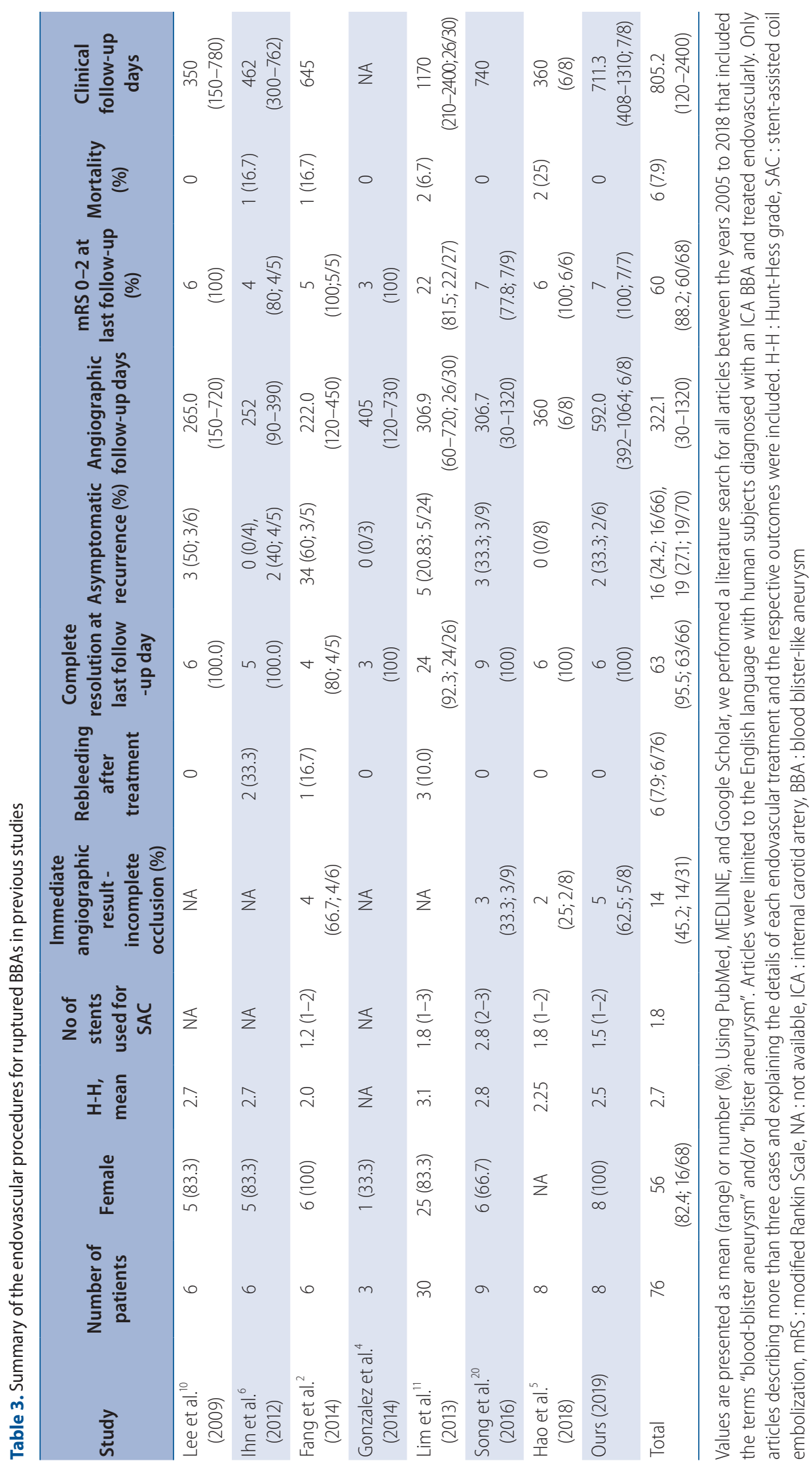


Table 4. Summary of rebleeding cases

\begin{tabular}{|c|c|c|c|c|c|}
\hline Case & Article & $\begin{array}{l}\text { Day of rebleeding } \\
\text { after initial bleeding }\end{array}$ & Method of retreatment & $\begin{array}{l}\text { Angiographic outcome } \\
\text { (months after initial treatment) }\end{array}$ & $\begin{array}{c}\text { Latest mRS score } \\
\text { (months after initial } \\
\text { treatment) }\end{array}$ \\
\hline 1 & Ihn et al. ${ }^{6}(2012)$ & 12 & Covered stent & NA & 6 (dead) \\
\hline 2 & Ihn et al. ${ }^{6}$ (2012) & 15 & SAC & Complete resolution (3) & $4(12)$ \\
\hline 3 & Fang et al. ${ }^{2}$ (2014) & 16 & $\begin{array}{l}\text { None (her relatives gave up } \\
\text { further treatment) }\end{array}$ & NA & $6($ dead $)$ \\
\hline 4 & Lim et al..$^{11}(2013)$ & 11 & Covered stent & NA & 6 (dead) \\
\hline 5 & Lim et al.. (2013) & 9 & Coiling & Complete resolution (6) & $3(54)$ \\
\hline 6 & Lim et al..$^{11}(2013)$ & 15 & Coiling & Complete resolution (34) & $4(28)$ \\
\hline
\end{tabular}

NA : not available, SAC : stent-assisted coil embolization

DSA demonstrated a rapid enlargement of the ruptured BBA. It had a relatively wide neck at $3.1 \mathrm{~mm}$ and a height of $2.3 \mathrm{~mm}$ (Fig. 3A). Emergency endovascular treatment was performed with a single Enterprise stent for neck remodeling and three coils for proper packing of the aneurysmal sac. A Raymond classification of 2 was achieved (Fig. 3B). No procedural complications were observed. During post-operative management, chemical angioplasty was performed five times within 2 weeks after admission due to symptomatic vasospasm. Recurrence or rebleeding of the treated BBA was not observed in this patient. With time, the patient's neurological status improved and she was discharged without any neurological deficits. In a follow-up DSA performed 6 months after the initial endovascular treatment, asymptomatic recurrence of the treated BBA was observed (Fig. 3C and D). Two intracranial stents (LVIS Blue $3.5 \times 17 \mathrm{~mm}$, 2ea; Microvention, Tustin, CA, USA) were deployed within the previously inserted stent. Gradual improvement and, eventually, complete angiographic resolution of the recurred aneurysm was observed in serial DSA studies (Fig. 3E and F).

\section{Pooled analysis}

The results of the pooled data is summarized in Fig. 4 and Table 3. Seven articles with a total of 68 cases were pooled for analysis. Seventy-six patients, including our eight patients, treated with SAC for ruptured BBAs of the supraclinoid ICA were enrolled. $82.4 \%$ of the patients were female. The median Hunt-Hess grade was $3.0 \pm 0.88$. The mean number of stents used for SAC was 1.8. Immediate angiographic results after treatment were available for 31 cases. These results showed an incomplete occlusion rate of $45.2 \%$. The occurrence of re- bleeding after treatment was 7.9\% (6 out of 76 cases). Sixteen cases out of $66(24.2 \%)$ had asymptomatic recurrence of the BBA. $88.2 \%$ (60 out of 68 ) showed good clinical outcome with mRS $0-2$ at their last clinical follow-up and their mean clinical follow-up days were 786.1 (range, 30-2400). The total mortality rate was $7.9 \%$ (6 out of 76). Radiology demonstrated a complete occlusion rate of $95.5 \%$ (63/66) by the last followup angiography (mean occurrence of angiographic follow-up was 322.1 days, ranging from 30 to 1320). We also analyzed occurrences of rebleeding and asymptomatic recurrence after initial treatment (Tables 4 and 5). While all patients with rebleeding after initial treatment indicated unfavorable outcomes (mRS 3-6), 86.7\% (13/15) of patients with asymptomatic recurrence showed favorable outcomes (mRS 0-2). Likewise, the final angiographic results from cases with asymptomatic recurrences were also favorable, revealing a complete occlusion rate of $93.8 \%$ (15/16). Twenty-four cases of asymptomatic recurrences after initial SAC were treated with additional coiling or stent-assisted coiling (19 procedures), covered stents (two cases), or additional stents (three cases).

\section{DISCUSSION}

The pooled analysis of SAC for treating ruptured BBAs in this study demonstrated that reconstructive SAC for ruptured BBAs provided favorable long-term clinical outcomes and stable angiographic outcomes. Although the high rate of BBA recurrence is a major drawback, almost all cases of recurrence were successfully treated with additional endovascular treatments, yielding long-term favorable outcomes and a high rate 
SAC for the Treatment of Ruptured BBAs | Roh H, et al.

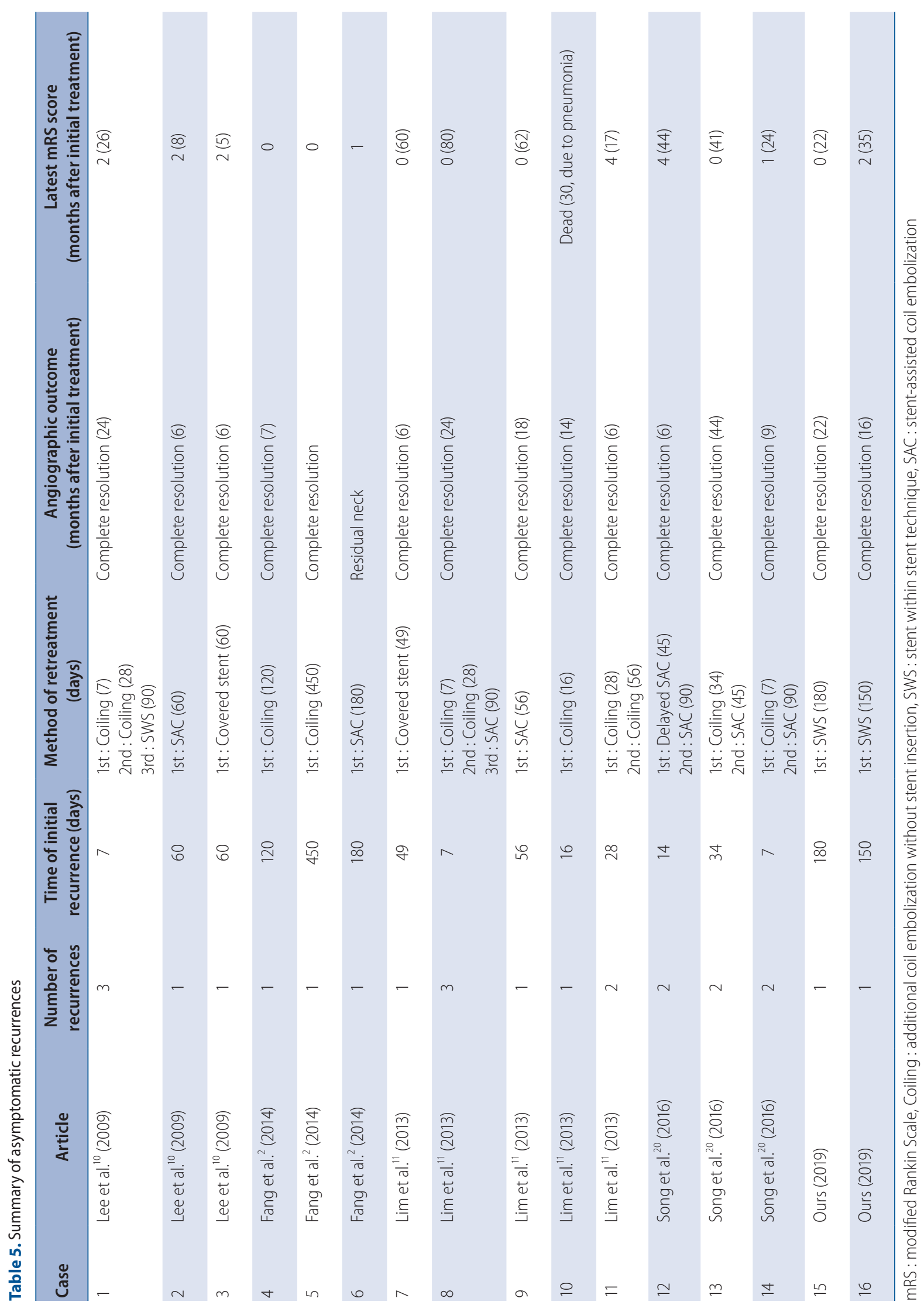


of complete aneurysm obliteration.

The pathology and the optimal treatments of BBA have not yet been established. Several pathology and surgical reports suggest that this aneurysm is a dissection of a diseased vessel wall $^{7,15)}$. Ishikawa et al. ${ }^{7)}$ described a ruptured BBA on the superior wall of the ICA as an abrupt disruption of the internal elastic lamina and media without collagenous coverage at the rupture point. They speculated that the border between the stiff, arteriosclerotic carotid wall and the normal, elastic carotid wall may be most vulnerable to hemodynamic stress. Mizutani et al. ${ }^{15)}$ proposed that BBA is a type 4 dissection with minimal disruption of the internal elastic lamina without intimal thickening and a dome comprised of fragile adventitia. Because direct surgical treatments of the aneurysm itself, including clipping or wrapping, are likely to cause premature rupture during surgical dissection, increasing mortality as well as a high risk of complications ${ }^{9-11,14,19-21)}$, they also suggested that direct surgical clipping of this wall defect is not the best treatment ${ }^{15)}$.

Endovascular reconstructive treatment with multiple stents has had relatively good results ${ }^{4-6,8,13,19)}$. Nevertheless, frequent recurrences and rebleeding of the treated aneurysm are still major drawbacks of endovascular reconstruction ${ }^{3,13,16)}$. In addition, the randomly interlinked and overlapped structs of multiple stents make it very difficult to re-select treated aneurysms through them and re-do additional coiling in the cases of recurrences ${ }^{2,3,20,22)}$. Recent meta-analysis of the treatment of 165 BBAs using flow-diverters without coils revealed favorable results with a complete occlusion rate of $72 \%$ at the last angiographic follow-up, a mortality rate of $5 \%$, and a rebleeding rate of $3 \%$. Although this technique has a relatively high morbidity rate of $26 \%$, this treatment modality seems to be effective and promising ${ }^{1)}$. Given the lack of evidence, the use of flow-diverters in treating ruptured aneurysms is still open for further investigation.

The procedure introduced in the current study has been performed in only a small number of clinical cases. Due to the rarity of this disease, a large prospective study has not been conducted. In order to overcome the selection bias and small number of cases, we pulled data regarding SAC for ruptured BBAs from published articles. Although there was insufficient data for immediate angiographic results, 45.2\% (14/31) showed incomplete occlusion immediately after SAC. Despite the low rate of immediate complete occlusion and a high rate of recur- rence, the overall mortality rate was relatively low at 7.9\% and good clinical outcomes, defined as mRS score $0-2$, were achieved in $88.2 \%$. Considering the high mortality rate of ruptured ICA BBAs, SAC is thought to be an effective treatment with reasonable clinical outcomes.

Prognosis of most rebleeding cases was poor; mRS $6(3 / 6$, $50 \%)$, mRS $4(2 / 6,33.3 \%)$, mRS $3(1 / 6,16.7 \%)$ and all of rebleeding occurred within relatively short time (16 days) after rupture. This implies that frequent and serial angiographic analysis in the early postoperative course is mandatory to detect any subtle change that can cause rebleeding. However, most asymptomatic recurrent cases were detected in the subacute or chronic phase with a wide range. These cases could be treated successfully with various endovascular treatments and, even in instances of multiple recurrence requiring repetitive treatments, all cases were treated with additional endovascular methods and their clinical and angiographic results were favorable. Final angiography revealed a complete occlusion rate of the pooled data of $95.5 \%$, which was higher than that of the flow-diverter. Theoretically, stents could provide support for endothelialization and subsequent stabilization of the diseased segment, while the coil would lessen the hemodynamic burden on the fragile, defective aneurysm wall, eventually reducing the high risk of rebleeding ${ }^{22}$. Thus, SAC could not only reduce the risk of early rebleeding, but also provided a safe access route to the recurrent lesion, allowing for various further treatment options with a relatively stable and safe clinical course.

The limitations of this study include a small sample size, selection bias, the lack of a control group for comparison, and its retrospective nature. Therefore, a generalized conclusion for this disease cannot be driven from this study. In addition, even though the techniques depicted in the pooled data appear to be the same as SAC, they differ in the type of stent used, number of stents deployed, packing rate of the coils, and technique of coil deployment. This study, however, is the first description of a pooled analysis of SAC for the treatment of ruptured supraclinoid ICA BBAs. Further investigation with larger patient populations and a prospective evaluation are clearly warranted in order to validate our results and provide a generalized conclusion for this disease. 


\section{CONCLUSION}

SAC of ruptured BBA on non-branching site of ICA showed good clinical and radiological outcome in our small case series and pooled data. This strategy of treatment seems to be reasonable in the aspect of treatment of diseased vascular segment with minimizing hemodynamic burden of the fragile dome of this specific aneurysm and a second chance for retreatment in recurrent cases. Further investigation of this technique for this fatal disease is warranted.

\section{CONFLICTS OF INTEREST}

No potential conflict of interest relevant to this article was reported.

\section{INFORMED CONSENT}

This type of study does not require informed consent.

\section{AUTHOR CONTRIBUTIONS}

\author{
Conceptualization : WY, SIS \\ Data curation : WY, HR \\ Formal analysis : HR \\ Funding acquisition : WY \\ Methodology : THK, JK \\ Project administration : WY \\ Visualization : WY, HR \\ Writing - original draft : HR \\ Writing - review \& editing : WY, HR
}

\section{ORCID}

$\begin{array}{ll}\text { Haewon Roh } & \text { https://orcid.org/0000-0002-7527-4407 } \\ \text { Junwon Kim } & \text { https://orcid.org/0000-0001-5394-3131 } \\ \text { Sang-il Suh } & \text { https://orcid.org/0000-0001-8933-0492 } \\ \text { Taek-Hyun Kwon } & \text { https://orcid.org/0000-0002-0176-5633 } \\ \text { Wonki Yoon } & \text { https://orcid.org/0000-0003-3715-0718 }\end{array}$

\section{- Acknowledgements}

This research was supported by Korea University Grant K2023221.

\section{References}

1. Cerejo R, Bain M, John S, Hardman J, Moore N, Hussain MS, et al. : Flow diverter treatment of cerebral blister aneurysms. Neuroradiology 59 : 1285-1290, 2017

2. Fang YB, Li Q, Wu YN, Zhang Q, Yang PF, Zhao WY, et al. : Overlapping stents for blood blister-like aneurysms of the internal carotid artery. Clin Neurol Neurosurg $123: 34-39,2014$

3. Gaughen JR Jr, Hasan D, Dumont AS, Jensen ME, McKenzie J, Evans AJ : The efficacy of endovascular stenting in the treatment of supraclinoid internal carotid artery blister aneurysms using a stent-in-stent technique. AJNR Am J Neuroradiol 31 : 1132-1138, 2010

4. Gonzalez AM, Narata AP, Yilmaz H, Bijlenga P, Radovanovic I, Schaller $\mathrm{K}$, et al. : Blood blister-like aneurysms: single center experience and systematic literature review. Eur J Radiol 83 : 197-205, 2014

5. Hao X, Li G, Ren J, Li J, He C, Zhang HQ : Endovascular patch embolization for blood blister-like aneurysms in dorsal segment of internal carotid artery. World Neurosurg $113:$ 26-32, 2018

6. Ihn YK, Kim SH, Sung JH, Kim TG : The efficacy of endovascular treatment of ruptured blood blister-like aneurysms using stent-assisted coil embolization. Interv Neuroradiol 18 : 432-441, 2012

7. Ishikawa T, Nakamura N, Houkin K, Nomura M : Pathological consideration of a "blister-like" aneurysm at the superior wall of the internal carotid artery: case report. Neurosurgery 40 : 403-405; discussion 405-406, 1997

8. Kim BM, Chung EC, Park SI, Choi CS, Won YS : Treatment of blood blister-like aneurysm of the internal carotid artery with stent-assisted coil embolization followed by stent-within-a-stent technique. Case report. J Neurosurg 107 : 1211-1213, 2007

9. Kim YW, Park IS, Baik MW, Jo KW : Endovascular treatment of blood blister-like aneurysms using multiple self-expanding stents. J Korean Neurosurg Soc 49 : 116-119, 2011

10. Lee BH, Kim BM, Park MS, Park SI, Chung EC, Suh SH, et al. : Reconstructive endovascular treatment of ruptured blood blister-like aneurysms of the internal carotid artery. J Neurosurg 110 : 431-436, 2009

11. Lim YC, Kim BM, Suh SH, Jeon P, Kim SH, Ihn YK, et al. : Reconstructive treatment of ruptured blood blister-like aneurysms with stent and coil. Neurosurgery 73 : 480-488, 2013

12. Matsubara N, Miyachi S, Tsukamoto N, Izumi T, Naito T, Haraguchi K, et al. : Endovascular coil embolization for saccular-shaped blood blister-like aneurysms of the internal carotid artery. Acta Neurochir (Wien) 153 : 287-294, 2011

13. Meckel S, Singh TP, Undrén P, Ramgren B, Nilsson OG, Phatouros $C$, et al. : Endovascular treatment using predominantly stent-assisted coil em- 
bolization and antiplatelet and anticoagulation management of ruptured blood blister-like aneurysms. AJNR Am J Neuroradiol 32 : 764-771, 2011

14. Meling TR, Sorteberg A, Bakke SJ, Slettebø H, Hernesniemi J, Sorteberg $\mathrm{W}$ : Blood blister-like aneurysms of the internal carotid artery trunk causing subarachnoid hemorrhage: treatment and outcome. J Neurosurg 108 : 662-671, 2008

15. Mizutani T, Miki Y, Kojima H, Suzuki H : Proposed classification of nonatherosclerotic cerebral fusiform and dissecting aneurysms. Neurosurgery 45 : 253-259; discussion 259-260, 1999

16. Nagasaki H, Narikiyo M, Nagayama G, Nagao S, Tsuboi Y, Kambayashi C : Hybrid procedure combining clip on wrapping and stent placement for ruptured supraclinoid blood blister-like aneurysm of the internal carotid artery. Clin Case Rep 5 : 285-289, 2017

17. Peschillo S, Cannizzaro D, Caporlingua A, Missori P : A systematic review and meta-analysis of treatment and outcome of blister-like aneurysms. AJNR Am J Neuroradiol 37 : 856-861, 2016

18. Rouchaud A, Brinjikji W, Cloft HJ, Kallmes DF : Endovascular treatment of ruptured blister-like aneurysms: a systematic review and meta-analy- sis with focus on deconstructive versus reconstructive and flow-diverter treatments. AJNR Am J Neuroradiol 36 : 2331-2339, 2015

19. Shah SS, Gersey ZC, Nuh M, Ghonim HT, Elhammady MS, Peterson EC : Microsurgical versus endovascular interventions for blood-blister aneurysms of the internal carotid artery: systematic review of literature and meta-analysis on safety and efficacy. J Neurosurg 127 : 1361-1373, 2017

20. Song J, Oh S, Kim MJ, Chung J, Lim YC, Kim BS, et al. : Endovascular treatment of ruptured blood blister-like aneurysms with multiple $(\geq 3)$ overlapping Enterprise stents and coiling. Acta Neurochir (Wien) 158 : 803-809, 2016

21. Yu B, Zheng J, Hong Y, Chen L, Xi Z, Yu M, et al. : Stent-assisted coil embolization of ruptured supraclinoid blood blister-like aneurysm of internal carotid artery. Turk Neurosurg 26 : 219-222, 2016

22. Zhu D, Fang Y, Yang $P$, Zhang $P$, Chen L, Xu Y, et al. : Overlapped stenting combined with coiling for blood blister-like aneurysms: comparison of low-profile visualized intraluminal support (LVIS) stent and non-LVIS stent. World Neurosurg 104 : 729-735, 2017 